\title{
ENHANCEMENT OF DRYOUT HEAT FLUX IN A DEBRIS BED BY FORCED COOLANT FLOW FROM BELOW
}

\author{
KWANG-HYUN BANG* and JONG-MYUNG KIM \\ Mechanical Engineering, Korea Maritime University \\ 1 Dongsamdong, Yeongdogu, Busan, 606-791, Korea \\ *Corresponding author. E-mail : khbang@hhu.ac.kr \\ Received March 05, 2009 \\ Accepted for Publication May 06, 2010
}

In the design of advanced light water reactors (ALWRs) and in the safety assessment of currently operating nuclear power plants, it is necessary to evaluate the possibility of experiencing a degraded core accident and to develop innovative safety technologies in order to assure long-term debris cooling. The objective of this experimental study is to investigate the enhancement factors of dryout heat flux in debris beds by coolant injection from below. The experimental facility consists mainly of an induction heater, a double-wall quartz-tube test section containing a steel-particle bed and coolant injection and recovery condensing loop. A fairly uniform heating of the particle bed was achieved in the radial direction and the axial variation was within $20 \%$. This paper reports the experimental data for $3.2 \mathrm{~mm}$ and $4.8 \mathrm{~mm}$ particle beds with a $300 \mathrm{~mm}$ bed height. The dryout heat density data were obtained for both the top-flooding and the forced coolant injection from below with an injection mass flux of up to $1.5 \mathrm{~kg} / \mathrm{m}^{2} \mathrm{~s}$. The dryout heat density increased as the rate of coolant injection increased. At a coolant injection mass flux of $1.0 \mathrm{~kg} / \mathrm{m}^{2} \mathrm{~s}$, the dryout heat density was $\sim 6.5 \mathrm{MW} / \mathrm{m}^{3}$ for the $4.8 \mathrm{~mm}$ particle bed and $\sim 5.6$ $\mathrm{MW} / \mathrm{m}^{3}$ for the $3.2 \mathrm{~mm}$ particle bed. The enhancement factors of the dryout heat density were 1.6-1.8.

KEYWORDS : Severe Accident, Ex-vessel Cooling, Particle Bed, Dryout Heat Flux

\section{INTRODUCTION}

In the very unlikely event of a severe reactor accident involving core melt and pressure vessel failure in conventional and advanced light water reactors (ALWRs), it is important to be able to identify the circumstances that would allow the molten core material to cool down, resolidify and bring the core debris to a stable coolable state .

One approach to achieve a stable coolable state is to quench the core melt after its relocation from the reactor pressure vessel into the reactor cavity. Ex-vessel debris coolability requires water to be present as a heat transfer medium to the ultimate heat sink over long periods to achieve a stable coolable state. Coolant water can be brought into the cavity either before the degraded core is relocated into the cavity (preflooding) or after the relocation (postflooding). The current knowledge, however, indicates that neither of these methods has demonstrated ultimate coolability (e.g., FARO tests [1], MACE tests [2]). The FARO test was performed to demonstrate the reactor safety system that was designed to provide water to be present in the reactor cavity to quench incoming molten core material. The MACE test was to demonstrate water addition atop the molten core pool in the reactor cavity.
One way of enhancing the ex-vessel debris coolability is to flow coolant in the debris bed from below, and some of the past studies have shown this concept could be successful (Alsmeyer and Tromm [3], Klockow et al. [4]). The COMET experiment involved the integral behavior of a molten pool ablating a sacrificial layer of concrete, and subsequently exposing water-filled injection nozzles that would drive melt-water mixing and the quench process.

If the volumetric heat removal rate is high enough, the high temperature molten core can cool and resolidify into the form of the debris bed. The size of the debris can vary according to the interfacial length scales of the melt droplets and coolant liquid and vapor. The porous characteristics of the debris bed also limit the heat removal rate. The maximum heat removal rate, i.e., the dryout heat flux, vary largely by the debris bed particle sizes and bed height. Past studies also showed that the dryout heat flux can be enhanced by a forced coolant flow from below.

The past work on the particle bed dryout heat flux is summarized in Table 1. The dependence on bed height and particle diameter of the dryout heat flux for a volumetrically heated particle bed was experimentally studied by Barleon et al. [5]. The bed was volumetrically heated by an induction coil heater and the coolant, water 
or Freon-113, was added to the top of the bed (top flooding). They reported that the dependence on particle size and bed height of the dryout heat flux was well predicted by the theory but that the absolute value was overpredicted. Hu and Theofanous [6] also conducted a dryout heat flux experiment for a top-flooded bed. They used a one-meter deep bed made up with electrically heated aluminum spheres and stone gravel of $\sim 8 \mathrm{~mm}$ in characteristic dimension. They reported a new finding for the dryout delay time in measuring dryout heat flux and recommended the Theofanous-Saito correlation for dryout heat flux in deep beds.

Enhancement of dryout heat flux by forced coolant flow from below were experimentally studied by Tsai and Catton [7], Cha et al. [8], Atkhen and Berthoud [9], and recently by Schafer et al. [10]. The bed heights in the first two experiments above were relatively shallow, $15 \mathrm{~cm}$ and $11 \mathrm{~cm}$. Atkhen and Berthoud used a rectangular bed with a $60 \times 10 \mathrm{~cm}$ cross section and a $50 \mathrm{~cm}$ height. Schafer et al. at IKE conducted an experiment using a circular crucible with a $0.64 \mathrm{~m}$ height and $0.125 \mathrm{~m}$ diameter.

Table 1. Past Work on Debris Bed Dryout Heat Flux

\begin{tabular}{l|c|c|c|c}
\hline Authors & $\begin{array}{c}\text { Particle } \\
\text { size } \\
(\mathrm{mm})\end{array}$ & $\begin{array}{c}\text { Bed } \\
\text { height } \\
(\mathrm{m})\end{array}$ & $\begin{array}{c}\text { Mass } \\
\text { flux } \\
\left(\mathrm{kg} / \mathrm{m}^{2} \mathrm{~s}\right)\end{array}$ & $\begin{array}{c}\text { Dryout heat } \\
\text { density } \\
\left(\mathrm{MW} / \mathrm{m}^{3}\right)\end{array}$ \\
\hline Barleon et al. [5] & $0.06-16$ & $<0.4$ & 0 & $3 \sim 4$ \\
\hline Tsai \& Catton [7] & $0.6-4.8$ & $<0.15$ & $0-0.56$ & $0.7 \sim 6$ \\
\hline Hu \& Theofanous [6] & $7-9$ & 1.02 & 0 & $0.6 \sim 1$ \\
\hline Cha et al. [8] & $1.5-5$ & 0.11 & $0-3.5$ & $9 \sim 26$ \\
\hline Atkhen \& Berthoud [9] & $2-7.2$ & $0.3-0.5$ & Not measured & $1.6 \sim 5.4$ \\
\hline Schafer et al. [10] & $3-6$ & 0.64 & $0.2-0.8$ & $1.27-2.08$ \\
\hline
\end{tabular}

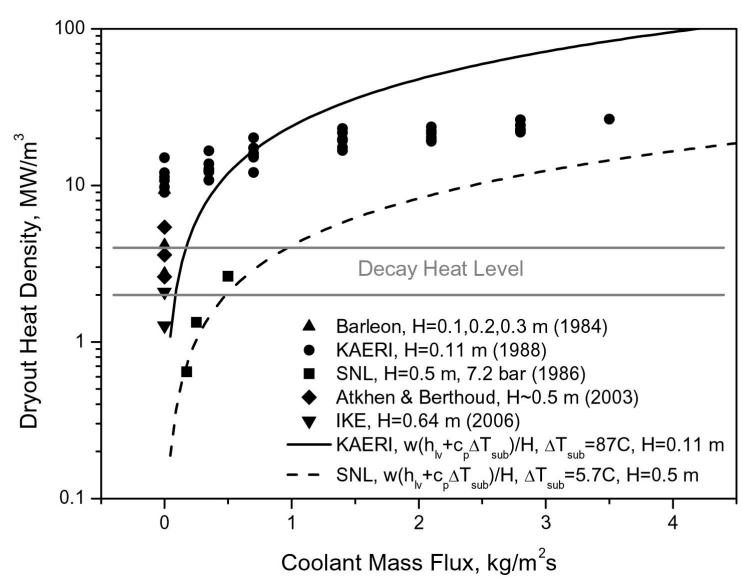

Fig. 1. Comparison of Past Experimental Data on Debris Bed Dryout Heat Density
They measured pressure gradients along the bed height for different flow modes and also measured the dryout heat flux for top flooding and coolant injection from below. Lindholm et al. [11] conducted a dryout heat flux experiment using a heterogeneous particle bed. Mixed particles of non-spherical gravel particles with a range of diameters of $0.25-10 \mathrm{~mm}$ were investigated using top flooding of water. They concluded significantly larger pressure drops than obtained for a uniform particle size bed.

Selected data for the dryout heat flux in the form of dryout heat density are shown in Fig. 1. In the literature the dryout heat flux is typically given in terms of the unit cross sectional area of the bed, and the dryout heat density given in Table 1 was obtained by dividing the dryout heat flux by the height of the bed. The reason for using dryout heat density instead of dryout heat flux is that it seems more illustrative when comparing it with decay heat. In Fig. 1, the enhancement of the dryout heat density by the forced coolant flow from below is quantitatively observed. Wide ranges of particle diameter and coolant mass flux were studied at Korea Atomic Energy Research Institute (KAERI, Cha et al. [8]), but their data showed limited usefulness due to the shallow bed height $(11 \mathrm{~cm})$ and bed diameter $(5 \mathrm{~cm})$.

Also shown in Fig. 1 is the possible range of decay heat of the core debris for typical LWRs. It is in the range of 2-4 MW/ $/ \mathrm{m}^{3}$ depending on the reactor thermal power rating as well as the accident scenario. In actual reactor conditions, the anticipated debris size may be a few millimeters or larger [1] and the debris bed can be deeper than $30 \mathrm{~cm}$ depending on the floor area of either the reactor cavity or a core catcher device. Considering these debris bed parameters of reactor conditions, it is clear that the existing dryout heat flux data for these ranges of particle size and bed height do not show a margin for assuring a stable coolable state of core debris in the reactor cavity if the cavity is just flooded or water is added on the top of the debris bed.

The curve of the thermal energy required for complete vaporization of saturated or subcooled injected coolant can be used to identify two regimes of limiting heat flux as shown in Fig. 1. In one regime where the dryout heat flux is greater than the vaporization heat the penetration of the overlying coolant into the bed is limited by countercurrent flooding phenomenon. In the other regime, the dryout heat flux is smaller than the vaporization heat of the injected coolant flow. In this regime the injected coolant does not vaporize completely at the top of the bed, and the limited heat flux may be due to a localized transition to film boiling at the particle surface.

Analytical models of predicting dryout heat flux in debris beds were proposed by Lipinski [12], Turland and Moore [13], Kim [14], and Burger and Berthoud [15]. Lipinski proposed a one-dimensional model which included the effects of both laminar and turbulent flow, two-phase 
friction, and capillary force and is applicable to debris with liquid entering the debris from the bottom. Kim applied a separated flow model based on the two-phase extended Ergun equations to a boiling porous medium and well predicted the top-flooding data of Barleon et al. [5].

The objective of the present study is to experimentally investigate the enhancement of dryout heat flux in debris beds with coolant flow from below for the key parameters relevant to reactor applications. This paper reports the experimental data for $3.2 \mathrm{~mm}$ and $4.8 \mathrm{~mm}$ particle beds with a $300 \mathrm{~mm}$ bed height and the implications to the exvessel debris bed coolabilty is discussed.

\section{EXPERIMENT}

An experimental setup for long-term coolability in volumetrically-heated particle beds with coolant injected from below was constructed. The experimental apparatus consisted mainly of an induction heater system, a quartz tube test section containing the particle bed, a condenser, and a water circulator. A schematic diagram of the apparatus is shown in Fig. 2.
The induction heater system consisted of a power supply and a control unit $(40 \mathrm{~kW}, 35 \mathrm{kHz})$, an induction coil and a cooling unit. The brine coolant of the cooling unit was directed to the condenser unit to condense the steam produced in the test section. The test section was a double-walled quartz tube with an inner diameter of 100 $\mathrm{mm}$ and a length of $400 \mathrm{~mm}$. Fabricated with a $3 \mathrm{~mm}$ thick quartz tube, it can contain a particle bed up to $300 \mathrm{~mm}$ high. Uniform-size steel balls were charged into the quartz tube to build the particle bed. The lower part of the test section (110 mm height) was filled with glass balls to separate the steel particle bed and the joining flange and also to distribute the water coolant uniformly over the cross section of the bottom of the particle bed when the coolant was injected from below.

The steam condenser was a shell-and-tube type heat exchanger and the coolant of the induction heater unit was also used as the condenser coolant. The condensate liquid flow rate was measured and the condensate liquid water returned to the water circulator. The water circulator supplied water coolant to the test section at a predetermined temperature either to the top of the test section (top-flooding tests) or from below the test section (forced upward flow

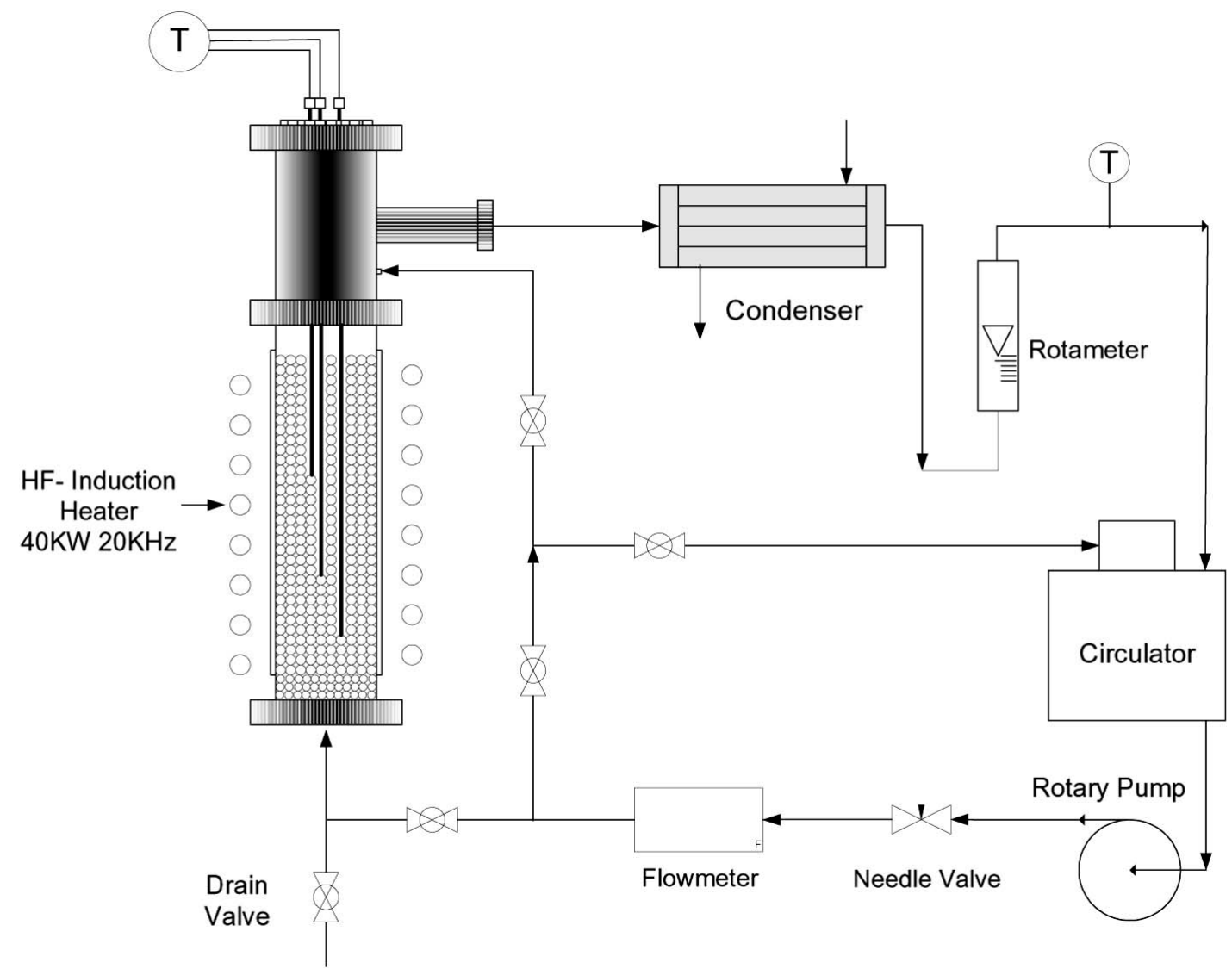

Fig. 2. A Schematic of the Experimental Apparatus 

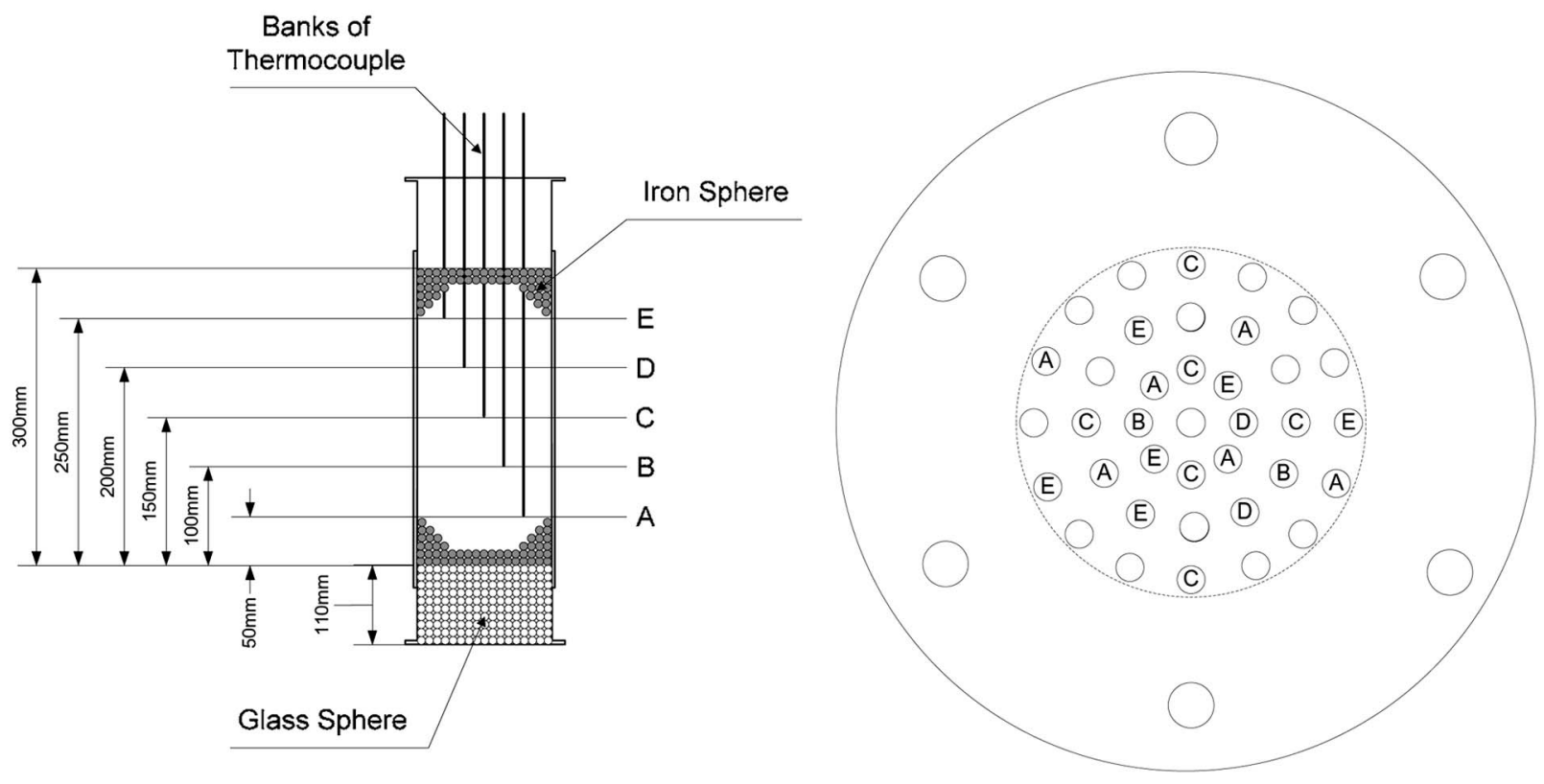

Fig. 3. Thermocouple Location in the Test Debris Bed

tests). The water coolant flow rate was controlled by a constant-speed pump and a needle valve.

Measurements were made for coolant temperatures inside the bed at various radial and axial locations and for the flow rates of the water coolant supply and condensate liquid flow. Twenty three chromel-alummel (K-type) thermocouples (stainless steel sheathed, $1.6 \mathrm{~mm}$ diameter) were inserted inside the bed at five axial locations, $50 \mathrm{~mm}$ apart, as shown in Fig. 3. The radial distribution of the thermocouples is also shown in the figure. A coriolis-type mass flow meter measured the coolant injection rate and a rotameter flow meter measured the condensate liquid flow rate. The thermocouples and flow meter signals were processed, monitored, and recorded on a PC-based data acquisition system (Labview).

\section{RESULTS AND DISCUSSION}

\subsection{Test Conditions}

An experiment was conducted to measure the dryout heat flux for debris beds with a $100 \mathrm{~mm}$ diameter and $300 \mathrm{~mm}$ height. The water coolant was supplied either from the top of the bed or from below. The bed was composed of steel particles with a uniform size $(3.2 \mathrm{~mm}$ or $4.8 \mathrm{~mm}$ in diameter) and volumetrically heated by an induction heater coil. The porosity of the particle bed was 0.37 for the $3.2 \mathrm{~mm}$ particle bed and 0.38 for the 4.8 $\mathrm{mm}$ particle bed.
In this experiment it was crucial to achieve uniform heat input throughout the bed, and for this purpose the particles of the bed had to be electrically isolated or completely conductive. Complete conductance between the steel particles was not plausible in this case. However, the natural rusting of the steel particles after several repeated boilings had built up a sufficient oxide coating over the particle surface, and this provided complete electrical insulation between the particles.

In order to measure the volumetric power density in the bed with induction heating, a liquid coolant was filled up to the top of the bed and induction power was applied at a predetermined level. The liquid temperature was allowed to rise to the boiling temperature. The twenty two thermocouple signals gave sensible heating of liquid, and these values were converted to the power density distribution using the following relations.

$$
\begin{gathered}
q^{\prime \prime \prime}=\frac{Q}{V}=\overline{\rho c}_{p} \frac{d T}{d t} \\
\bar{\rho}=\rho_{\text {steel }}(1-\varepsilon)+\rho_{\text {water }} \varepsilon \\
\bar{c}_{p}=\frac{1}{\bar{\rho}}\left[\rho_{\text {steel }}(1-\varepsilon) c_{p, \text { steel }}+\rho_{\text {water }} \varepsilon c_{p, \text { water }}\right]
\end{gathered}
$$

Natural circulation of the coolant in the bed caused a nonlinear rise of temperature, particularly in the upper part of the bed. Considering the construction of the induction 
coil and the particle bed characteristics, the center of the bed showed a higher power density and the top and the bottom parts of the bed showed a lower power density. The axial variation of the power density was within $\sim 20 \%$. The radially-averaged power density at different power levels for the induction unit is shown in Fig. 4. The average power density over the whole bed shows good linearity with the unit power level. Then the best-fitted linear function was used to read the power density in the experiment (Fig. 5).

The volumetric power density was also verified by comparing it with the condensation heat removal rate of the steam produced. The condensate water flow rate and the temperature were measured. A stable steady-state operation of the boiling in the test section and condensation in the condenser of the loop was achieved. The condensate liquid flow rate multiplied by the latent heat of the vaporization of the coolant is equal to the heat added in the
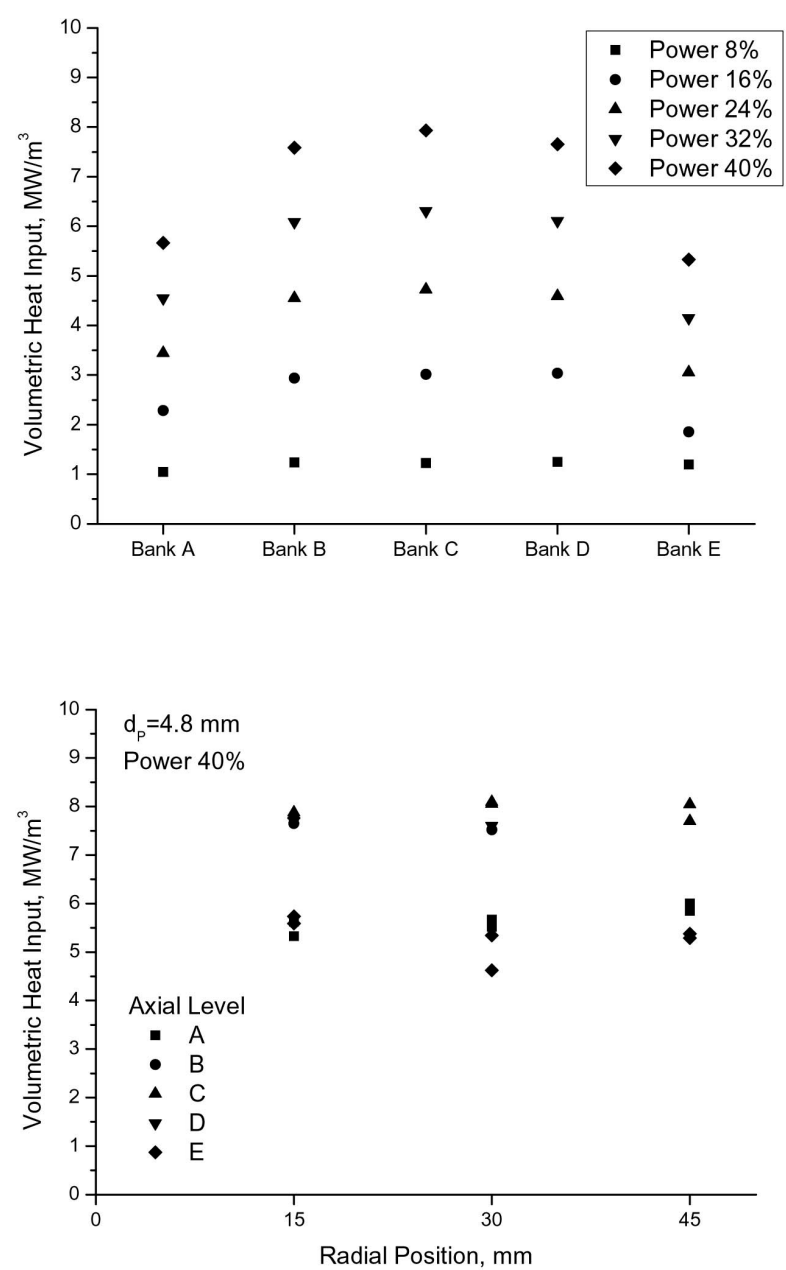

Fig. 4. Axial and Radial Distributions of Volumetric Heat Input in Induction Heating of the Particle Bed $\left(\mathrm{d}_{\mathrm{p}}=4.8 \mathrm{~mm}\right)$ test section to boil the liquid coolant. A comparison between the power input from the measured volumetric heat (Fig. 5) and the latent heat of the condensate showed a fairly good agreement within $3 \%$, indicating the present method of volumetric heat input measurement is reasonably accurate.

\subsection{Dryout Heat Density}

The first set of tests used top flooding to obtain the topflooding data for the present experiment's bed composition and geometry and also to verify the present experimental method by comparing our data with the past data of experiments with similar geometry. The nearly saturated liquid coolant was, in this case, continuously added to the top of the bed and the induction heating power was increased by a step from a lower level until one or a group of thermocouples showed a sharp increase, as shown in Fig. 6. With top-flooding the dryout always occurred at

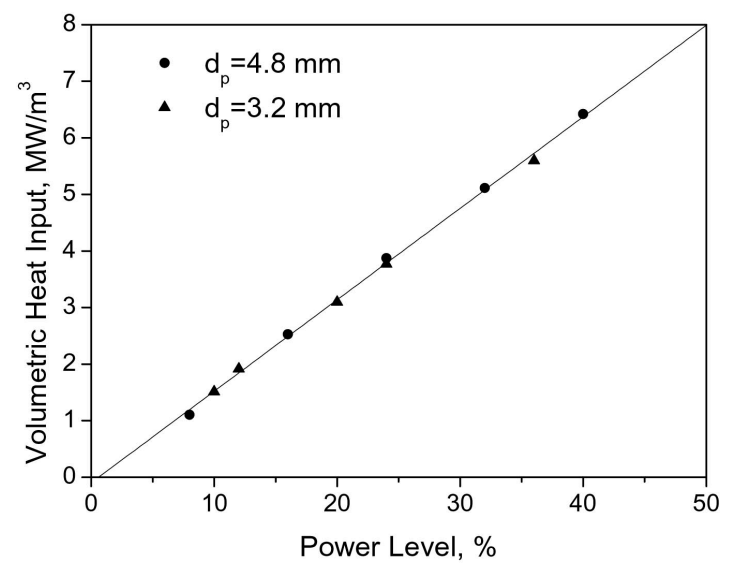

Fig. 5. Average Volumetric Heat Input at Various Induction Heater Power Levels

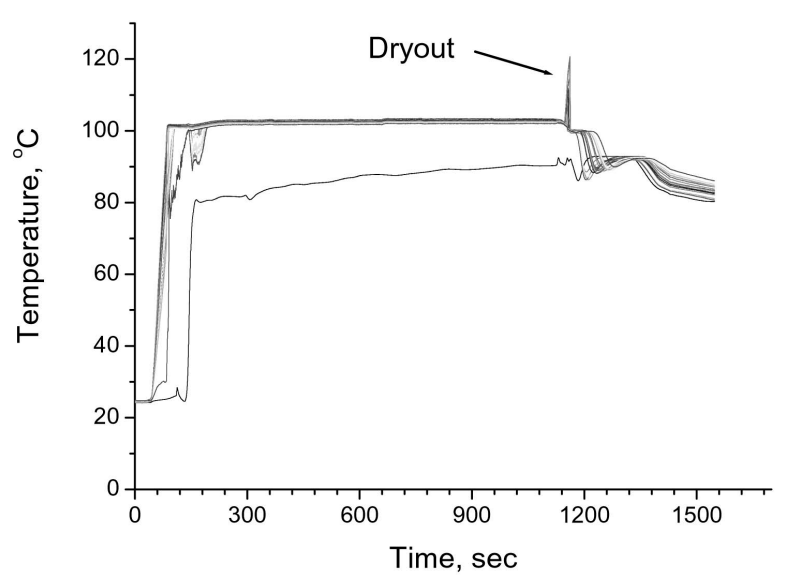

Fig. 6. Typical Debris Bed Temperature Response at Dryout Incipiency 
the bottom of the bed.

For the $4.8 \mathrm{~mm}$ particle bed, the top-flooding dryout heat density was $\sim 4.0 \mathrm{MW} / \mathrm{m}^{3}$ as shown in Fig. 7 ; this value falls within the range of the past experimental data. The coolant boiling rate corresponding to this amount of heat input is about $0.5 \mathrm{~kg} / \mathrm{m}^{2} \mathrm{~s}$ in terms of mass flux. Thus, when the coolant was injected only from below the bed, the dryout occurred whenever the power input was greater that the heat required to evaporate all the coolant injected from below. For the $3.2 \mathrm{~mm}$ particle bed, the top-flooding dryout heat density was $\sim 2.9 \mathrm{MW} / \mathrm{m}^{3}$ as also shown in Fig. 7.

For the tests with the coolant flowing from the bottom of the particle bed, the nearly saturated liquid coolant was continuously injected from the bottom of the test section at a preset rate. The induction heating power was increased by a step from a lower level until one of thermocouples showed a sharp increase. Note that there was a layer of glass beads in a section with a $110 \mathrm{~mm}$ height between the bottom of the test section and the steel bead particle bed to distribute the injected coolant over the cross section of the test section. When the coolant injection rate was in a range of 0.25 to $1.5 \mathrm{~kg} / \mathrm{m}^{2} \mathrm{~s}$, the measured dryout heat densities were as shown in Fig. 7. The line in the figure is the evaporation heat of the complete vaporization of the coolant flow. The dryout heat density increased as the coolant injection rate increased. For the $4.8 \mathrm{~mm}$ particle bed the dryout heat density was $\sim 4.6 \mathrm{MW} / \mathrm{m}^{3}$ at a coolant mass flux of $0.5 \mathrm{~kg} / \mathrm{m}^{2} \mathrm{~s}$ and $7.9 \mathrm{MW} / \mathrm{m}^{3}$ at a coolant mass flux of $1.5 \mathrm{~kg} / \mathrm{m}^{2} \mathrm{~s}$. For the $3.2 \mathrm{~mm}$ particle bed the dryout heat density was $\sim 2.9 \mathrm{MW} / \mathrm{m}^{3}$ at a coolant mass flux of $0.25 \mathrm{~kg} / \mathrm{m}^{2} \mathrm{~s}$ and $5.6 \mathrm{MW} / \mathrm{m}^{3}$ at a coolant mass flux of 1.0 $\mathrm{kg} / \mathrm{m}^{2} \mathrm{~s}$. The regime transition from the flooding controlled dryout to bulk film boiling seemed to occur at about 0.75 $\mathrm{kg} / \mathrm{m}^{2} \mathrm{~s}$, as suggested by the cross point of the evaporation heat line and the dryout heat data curve.

The present dryout heat density data for the bed height

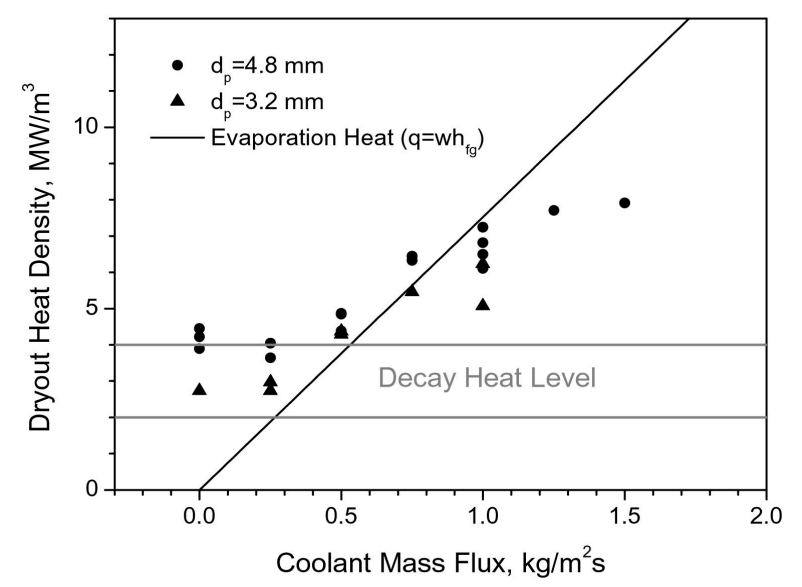

Fig. 7. Measured Dryout Heat Density in $3.2 \mathrm{~mm}$ and $4.8 \mathrm{~mm}$ Particle Beds of $300 \mathrm{~mm}$ and particle sizes of $3.2 \mathrm{~mm}$ and $4.8 \mathrm{~mm}$ can be compared with the past studies as shown in Fig. 1. The present data of dryout heat density in the case of zero flow (top-flooding) agrees well with the past data. Comparing with the KAERI data (Cha et al. [4]), the coolant flow from below also shows the effect of bed height, as the debris bed height of Cha et al. was $0.1 \mathrm{~m}$ while this study's bed height was $0.3 \mathrm{~m}$.

Fig. 7 also shows the estimated decay heat level at the time when the degraded core is relocated into the reactor cavity. The volumetric decay heat level could be 2-4 $\mathrm{MW} / \mathrm{m}^{3}$ depending on the thermal power rating of the reactor (AP1000 or APR1400). The comparison of this study's dryout heat density data with the possible decay heat density may imply that if the particle size of the debris bed in the case of an actual reator condition is greater than $3.2 \mathrm{~mm}$ (Hohmann et al. [1]) the coolant addition onto the top of the debris bed alone is not sufficient for maintaining the debris bed in a long-term coolable state as the dryout heat density is smaller than the volumetric decay heat. Flowing coolant from the debris bed bottom can, however, increase the dryout heat density. If the coolant flow mass flux is greater than $0.5 \mathrm{~kg} / \mathrm{m}^{2} \mathrm{~s}$, the dryout heat density becomes greater than the decay heat, assuring long-term debris coolability in ex-vessel.

\subsection{Comparison with Model Prediction}

Lipinski [12] proposed a one-dimensional model which included the effects of both laminar and turbulent flow, two-phase friction, gravity, and capillary force, and this model is applicable to both uniform and stratified debris as well as debris with liquid entering from the debris bottom. If the bed is uniform and deep enough, i.e., the bed height is greater than the capillary head $\lambda_{c}=6 \sigma \cos \theta$ $(1-\varepsilon) / d \varepsilon\left(\rho_{l}-\rho_{v}\right) g$, the capillary force can be ignored and the Linpinski's formulation of the relation between dryout heat flux (q) and effective saturation (s) appears as follows.

$$
\begin{gathered}
-\left(\rho_{l}-\rho_{v}\right) g+\frac{1.75(1-\varepsilon) q^{2}}{h_{l v}{ }^{2} \varepsilon^{3} d}\left[\frac{1}{\rho_{v}(1-s)^{5}} \pm \frac{1}{\rho_{l} s^{5}}\right] \\
+\frac{150(1-\varepsilon)^{2} q}{h_{l v} \varepsilon^{3} d^{2}}\left[\frac{\mu_{v}}{\rho_{v}(1-s)^{3}}+\frac{\mu_{l}}{\rho_{l} s^{3}}\right]+\frac{(1-\varepsilon) w}{\rho_{l} \varepsilon^{3} d} \\
\times\left[ \pm \frac{1.75 w}{s^{5}} \mp \frac{3.5 q}{s^{5} h_{l v}}-\frac{150(1-\varepsilon) \mu_{l}}{s^{3} d}\right]=0
\end{gathered}
$$

Here, the upper sign applies for $q>w h_{l v}$ and the lower sign applies for $q<w h_{l v}$. In the present study's experimental conditions of $3.2 \mathrm{~mm}$ steel particles and water, the capillary head $\lambda_{c}=0.022 \mathrm{~m}$; thus Equation (2) can be applied to the particle beds in the present study.

The prediction of Lipinski's model for top-flooded beds $(w=0)$ was compared with the measured data for two 
particle sizes, shown in Fig. 8, and a good agreement was found. The effect of particle size is also seen as $q \sim \sqrt{d}$. For coolant flowing from the debris bed bottom, Equation (2) can be solved for the axial distribution of effective saturation, s, and the power at the dryout incipient can be determined. The predictions are shown in Fig. 9 with the experimental data. The agreement between the data and the predictions appears good up to a coolant mass flux of about $0.75 \mathrm{~kg} / \mathrm{m}^{2} \mathrm{~s}$, but beyond this point of mass flux the model overpredicts the data. The predicted dryout heat density approaches the line of vaporization heat $\left(q<w h_{l v}\right)$. The experimental data shows that the enhancement of dryout heat flux with an increasing coolant mass flux becomes slower at higher coolant mass fluxes, when compared with the increase of evaporation energy of the coolant flow, as shown in Fig. 9.

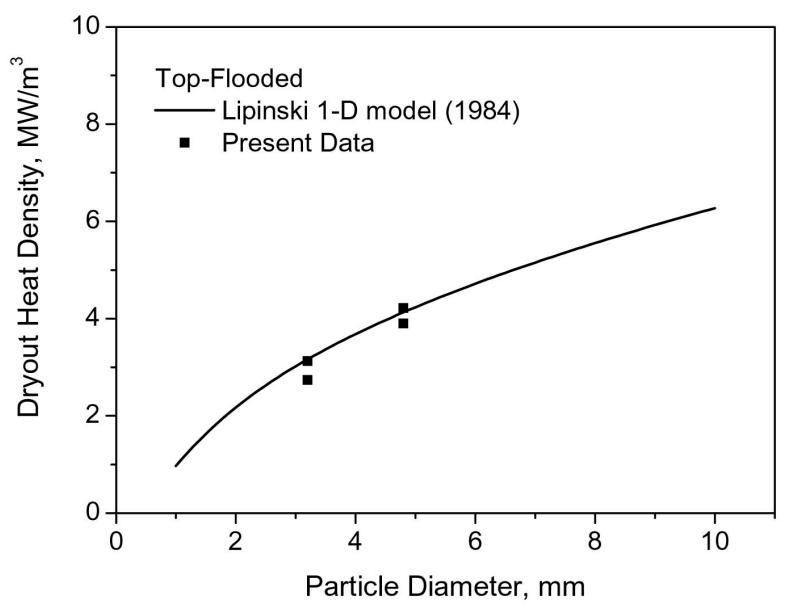

Fig. 8. Comparison of Measured Dryout Heat Density with the Prediction of the Lipinski 1-D Model for Top-flooded Beds

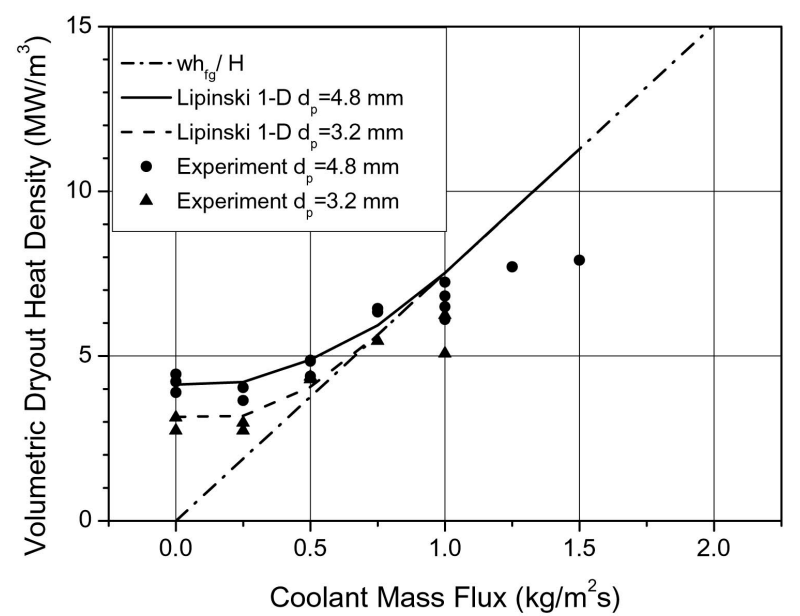

Fig. 9. Comparison of Measured Dryout Heat Density with Prediction of the Lipinski 1-D Model for Coolant Injection from the Debris Bottom

\section{CONCLUSIONS}

Enhancement of dryout heat flux in debris beds with a coolant flow from below was experimentally studied. A fairly uniform heating of the particle bed was achieved in the radial direction and the axial variation was within $20 \%$. For $3.2 \mathrm{~mm}$ and $4.8 \mathrm{~mm}$ particle beds with a $300 \mathrm{~mm}$ bed height, the dryout heat density data were obtained for both top-flooding and forced coolant injection from below with an injection mass flux up to $1.5 \mathrm{~kg} / \mathrm{m}^{2} \mathrm{~s}$. The dryout heat density increased as the rate of coolant injection increased. At the coolant injection mass flux of $1.0 \mathrm{~kg} / \mathrm{m}^{2} \mathrm{~s}$, the dryout heat density was $\sim 6.5 \mathrm{MW} / \mathrm{m}^{3}$ for the $4.8 \mathrm{~mm}$ particle bed and $\sim 5.6 \mathrm{MW} / \mathrm{m}^{3}$ for the $3.2 \mathrm{~mm}$ particle bed. The enhancement factors of dryout heat flux by coolant injection from below were 1.6-1.8. However, the enhancement of dryout heat flux became slower at higher coolant mass fluxes, when compared with the increase of evaporation energy of the coolant flow.

The comparison of the present dryout heat flux data with the possible decay heat implies that the coolant addition onto the top of the debris bed alone is not sufficient to maintain the debris bed in a long-term coolable state. However, if the coolant is injected from the debris bottom at a rate greater than $0.5 \mathrm{~kg} / \mathrm{m}^{2} \mathrm{~s}$, the dryout heat density becomes greater than the decay heat, assuring long-term debris coolability in ex-vessel. As for the analytical modeling of debris bed dryout heat flux, the Lipinski's 1$\mathrm{D}$ model shows a good prediction of the experimental data up to the coolant mass flux of about $0.75 \mathrm{~kg} / \mathrm{m}^{2} \mathrm{~s}$, but beyond this point the model overpredicts the data.

The result of the present work has the limitation of having uniform particle size, while in the case of an actual reactor condition there is a variation of particle size in the direction of bed height, depending on the melt jet breakup or melt-water mixture characteristics during the quenching process. Porosity can also vary substantially. The uncertainties associated with the variation of particle size as well as porosity should be identified. For the effect of particle size and the effect related to their distribution in a nonhomogeneous pool, a study of two-dimensional flows within a larger debris bed can be of benefit, such as the ongoing studies of the PEARL program and SARNET. In addition, the coolant flow from the bed bottom can be achieved without a pump if there is downcomer-like side space in the bed, in which case there would be a natural upward flow, though the flow rate could hardly be specified in this case. This natural flow will be further investigated in the future.

\section{NOMENCLATURE}

$\begin{array}{ll}\mathrm{c}_{\mathrm{p}} & \text { Specific heat, } \mathrm{J} / \mathrm{kgK} \\ \mathrm{d} & \text { Particle diameter, } \mathrm{m} \\ \mathrm{g} & \text { Gravitational constant }(=9.8 \mathrm{~m} / \mathrm{s})\end{array}$


H Bed height, m

$\mathrm{h}_{\mathrm{lv}} \quad$ Latent heat of vaporization, $\mathrm{J} / \mathrm{kg}$

Q Total heat input, W

q Heat flux, W/m²

q", Volumetric heat input, W/m $\mathrm{m}^{3}$

s Effective saturation

$\mathrm{T}$ Temperature, $\mathrm{K}$

$\mathrm{t}$ Time, sec.

V Volume, $\mathrm{m}^{3}$

w Mass flux, $\mathrm{kg} / \mathrm{m}^{2} \mathrm{~s}$

\section{Greeks}

\section{$\varepsilon \quad$ Porosity}

$\lambda_{c} \quad$ Capillary head, $m$

$\mu \quad$ Viscosity, $\mathrm{Pa} \cdot \mathrm{s}$

$\theta \quad$ Contact angle

$\rho \quad$ Density, $\mathrm{kg} / \mathrm{m}^{3}$

$\sigma \quad$ Surface tension, N/m

\section{Subscripts}

$l \quad$ Liquid

steel steel debris

sub subcooling

$v \quad$ Vapor

water water coolant

\section{ACKNOWLEDGEMENTS}

This work has been funded by the Ministry of Education, Science and Technology through Korea-USA I-NERI Project and the Ministry of Knowledge and Economy (Nuclear Power R\&D Program).

\section{REFERENCES}

[ 1 ] Hohmann. H. et al., "FCI Experiments in Corium/Water System," Nucl. Eng. Des., 177, p. 339-349 (1997).

[2 ] Farmer, M. T. et al., "Results of MACE Test M0 and M1," Proceedings of the 2nd OECD (NEA) CSNI Specialist's
Meeting on Molten Core Debris-Concrete Interactions, Karlsruhe, Germany (1992).

[ 3 ] Alsmeyer, H. and Tromm, W., "The COMET Concept for Cooling Core Melts: Evaluation of the Experimental Studies and Use in the EPR," FZKA 6186, EXV-CSC(99)D036 (1999).

[4] Klockow, H. B. et al., "Simulant Melt Pool Quench Behavior via Coolant Injection from Below," Proc. 10th Int. Topical Meeting on Nuclear Reactor Thermal Hydraulics (NURETH-10), Seoul, Korea (2003).

[ 5 ] Barleon, L. et al., "Cooling of Debris Beds," Nuclear Technology, 65, pp. 67-86 (1984).

[6] Hu, K. and Theofanous, T. G., "On the Measurement and Mechanism of Dryout in Volumetrically Heated Coarse Particle Beds," Int. J. Multiphase Flow, 17(4), pp. 519532 (1991).

[7] Tsai, F. P. and Catton, I., "On Dryout Heat Flux and Pressure Drop of a Submerged Inductively Heated Bed Flow From Below," Proc. Nat. Heat Transfer Conf., AIChe Symposium Series, 79(225), pp. 296-302 (1983).

[ 8 ] Cha, J. H. et al., "Forced Flow Dryout Heat Flux in Heat Generating Debris Bed," J. Korean Nuclear Society, 18(4), pp. 273-280 (1986).

[9] Atkhen, K. and Berthoud, G., "Experimental and Numerical Investigations on Debris Bed Coolability in a Multidimensional and Homogeneous Configuration with Volumetric Heat Source," Nuclear Technology, 142, pp. 270-282 (2003).

[10] Schafer, P., Groll, M., and Kulenovic, R., "Basic investigations on debris cooling," Nucl. Eng. Des, 236, pp. 2104-2116 (2006).

[11] Lindholm, I. et al., "Dryout heat flux experiments with deep heterogeneous particle bed," Nucl. Eng. Des, 236, pp. 2060-2074 (2006).

[12] Lipinski, R. J., “A Coolability Model for Postaccident Nuclear Reactor Debris," Nuclear Technology, 65, pp. 5366 (1984).

[13] Turland, B. D. and Moore, K., "Debris Bed Heat Transfer with Top and Bottom Cooling," Proc. Nat. Heat Transfer Conf., AIChe Symposium Series, 79(225), pp. 250-255 (1983).

[14] Kim, S. H., "A Modeling of the Liquid-Vapor Flow in a Self-Heated Porous Medium: With Application to the Dryout Limits," J. Nuclear Science and Technology, 33(9), pp. 686-695 (1996).

[15] Burger, M. and Berthoud, G., "Basic laws and coolability of particulate debris: comments on the status and present contributions," Nucl. Eng. Des, 236, pp. 2049-2059 (2006). 